\title{
Low-flow and high-flow neurosurgical bypass and anastomosis training models using human and bovine placental vessels: a histological analysis and validation study
}

\author{
*Evgenii Belykh, MD,1,2 Ting Lei, MD,1 Sam Safavi-Abbasi, MD,1 Kaan Yagmurlu, MD, ${ }^{1}$ \\ Rami O. Almefty, MD, ${ }^{1}$ Hai Sun, MD, PhD, ${ }^{1}$ Kaith K. Almefty, MD, ${ }^{1}$ Olga Belykh, MD, PhD, ${ }^{3}$ \\ Vadim A. Byvaltsev, MD, PhD, ${ }^{2,3}$ Robert F. Spetzler, MD, ${ }^{1}$ Peter Nakaji, MD, ${ }^{1}$ and Mark C. Preul, MD1 \\ 1Division of Neurological Surgery, Barrow Neurological Institute, St. Joseph's Hospital and Medical Center, Phoenix, Arizona; \\ 2Laboratory of Neurosurgery, Irkutsk Scientific Center of Surgery and Traumatology; and ${ }^{3}$ rrkutsk State Medical University, \\ Irkutsk, Russia
}

\begin{abstract}
OBJECTIVE Microvascular anastomosis is a basic neurosurgical technique that should be mastered in the laboratory. Human and bovine placentas have been proposed as convenient surgical practice models; however, the histologic characteristics of these tissues have not been compared with human cerebral vessels, and the models have not been validated as simulation training models. In this study, the authors assessed the construct, face, and content validities of microvascular bypass simulation models that used human and bovine placental vessels.

METHODS The characteristics of vessel segments from 30 human and 10 bovine placentas were assessed anatomically and histologically. Microvascular bypasses were performed on the placenta models according to a delineated training module by "trained" participants (10 practicing neurosurgeons and 7 residents with microsurgical experience) and "untrained" participants (10 medical students and 3 residents without experience). Anastomosis performance and impressions of the model were assessed using the Northwestern Objective Microanastomosis Assessment Tool (NOMAT) scale and a posttraining survey.
\end{abstract}

RESULTS Human placental arteries were found to approximate the $M_{2}-M_{4}$ cerebral and superficial temporal arteries, and bovine placental veins were found to approximate the internal carotid and radial arteries. The mean NOMAT performance score was $37.2 \pm 7.0$ in the untrained group versus $62.7 \pm 6.1$ in the trained group ( $<0.01$; construct validity). A $50 \%$ probability of allocation to either group corresponded to 50 NOMAT points. In the posttraining survey, 16 of 17 of the trained participants (94\%) scored the model's replication of real bypass surgery as high, and 16 of 17 (94\%) scored the difficulty as "the same" (face validity). All participants, 30 of $30(100 \%)$, answered positively to questions regarding the ability of the model to improve microsurgical technique (content validity).

CONCLUSIONS Human placental arteries and bovine placental veins are convenient, anatomically relevant, and beneficial models for microneurosurgical training. Microanastomosis simulation using these models has high face, content, and construct validities. A NOMAT score of more than 50 indicated successful performance of the microanastomosis tasks.

http://thejns.org/doi/abs/10.3171/2015.8.JNS151346

KEY WORDS cerebral revascularization; NOMAT; placenta; microvascular anastomosis training; surgical simulation; neurosurgical training; surgical practice; vascular disorders

$\mathrm{N}$ EUROSURGICAL vascular cases often require complex microvascular bypass techniques, such as those used in operative corrections for moyamoya disease, $, 726,32$ cerebral aneurysms, ${ }^{9,13,14,19}$ and intracranial tumors. ${ }^{30,31}$ Therefore, simple and accessible models for microvascular anastomosis training are increasingly es- sential for providing a means for refining and preserving skills. Several models, including chicken wings, ${ }^{12,17}$ turkey wings, ${ }^{1}$ rats, ${ }^{15}$ human cadavers, ${ }^{24,29}$ and plastic tubing, ${ }^{22}$ have been proposed. However, these models are still less than ideal for various reasons, such as vessel diameter diversity, cost-effectiveness, artifacts due to storage (e.g.,

ABBREVIATIONS ACA = anterior cerebral artery; ICA = internal carotid artery; MCA = middle cerebral artery; NOMAT = Northwestern Objective Microanastomosis Assessment Tool; PICA = posterior inferior cerebellar artery; $\mathrm{RA}=$ radial artery; STA = superficial temporal artery.

SUBMITTED June 10, 2015. ACCEPTED August 14, 2015.

INCLUDE WHEN CITING Published online January 22, 2016; DOI: 10.3171/2015.8.JNS151346.

* Evgenii Belykh, MD, and Ting Lei, MD, contributed equally to this manuscript. 
freezing), or poor tactile simulation of human arteries. We have developed microvascular anastomosis training models that use human and bovine placentas, but there have been no analyses that assess the usefulness of these models for neurovascular training based on the histologic characteristics of the tissues or validation of the actual surgical techniques, as appropriate. In this article, we describe our experience and validation of the use of fresh human placental arteries and bovine placental arteries and veins for performing microvascular anastomosis training.

\section{Methods \\ Obtaining Placentas}

This project was approved by the Institutional Review Board for Human Subjects at Barrow Neurological Institute (St. Joseph's Hospital and Medical Center) and the Ethics Committee of the Irkutsk Scientific Center of Surgery and Traumatology. Informed consent regarding the use of placentas for surgical practice was obtained from appropriate obstetrics patients, who then donated their placentas. The placentas were then screened for infectious diseases. A total of 30 human placentas from both of the participating institutions were collected. Ten bovine placentas were obtained from local dairy farms (within a 30-mile radius of Phoenix, Arizona). The cleaned placentas could be kept under refrigeration for approximately 1 week and were then discarded.

\section{Anatomical and Histological Study}

Mammalian placenta is formed from embryonic fetal envelopes of the chorion and allantois. Conceptually, 4 types of mammalian placenta are distinguished based on the distribution of the villi on the fetal membrane surface: diffuse, cotyledonary, ringed, and discoid. Bovine placenta is of the cotyledon type, in which the villi are localized in multiple circumscribed areas (i.e., the cotyledons). Human placenta is of the discoid type, in which the villi are arranged in a single circular plate. ${ }^{5}$ We chose bovine cotyledonary placenta for study and comparison with human placenta due to its large size and wide availability from local dairy farms.

\section{Gross Structure of Human Placenta}

The average human placenta has a diameter of 17.0 to $20.0 \mathrm{~cm}$, a thickness of 2.0 to $2.5 \mathrm{~cm}$, and a weight of $500 \mathrm{~g}$. There are 2 surfaces on the human placenta: the fetal surface faces the fetus and is covered with smooth amnion, and the maternal surface is divided into 15 to 16 cotyledons that compose the chorion and is adherent to the uterine wall. The human umbilical cord contains 2 arteries and 1 vein and usually attaches to the center of the placenta, from which the vessels radiate on the fetal surface. While human placental microcirculation has been well studied, less attention has been given to the vasculature of the placental surface. Studies by Bekov ${ }^{4,5}$ proposed a classification of the fetal surface arteries into first-, second-, and third-division segments (Fig. 1 left).

\section{Gross Structure of Bovine Placenta}

The gross structure of the bovine placenta is a cone-
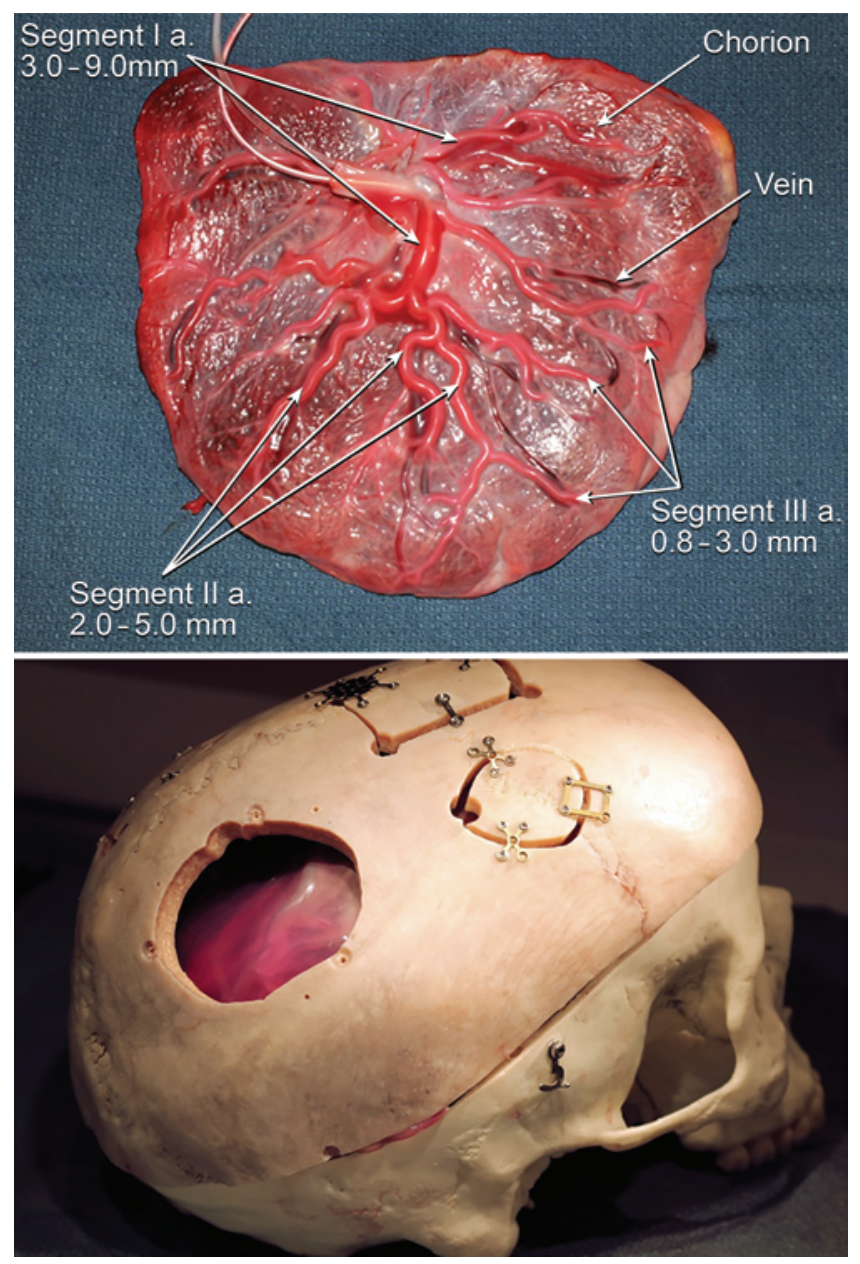

FIG. 1. Upper: Human placenta with pressurized flow in arteries. Bekov ${ }^{5}$ defined the first-order segments as those diverging from the umbilical cord. The third-order segments are the end segments on the fetal surface that dive into the chorion to provide circulation into distinct cotyledons. The second-order segments are located between the first and third segments. Lower: Human placenta placed into a skull to simulate in situ bypass surgery. a. = artery.

shaped sac that has a diameter of 10 to $45 \mathrm{~cm}$, a length of $90 \mathrm{~cm}$, and an average weight of $5 \mathrm{~kg}$. The average number of cotyledons in bovine placentas varies from 80 to 120 . Cotyledons have cone-shaped formations that range in diameter from 3 to $9 \mathrm{~cm}$ with massive villi structures. The bovine umbilical cord contains 2 arteries and 2 veins. The overall mass and villous surface of the bovine placenta is roughly 10 times larger than the human placenta. ${ }^{27,34}$

Bovine placenta has 3 types of arterial branching patterns: a large artery that branches perpendicularly in regular intervals of 5 to $6 \mathrm{~cm}$; a large artery that gradually divides in an alternative tree-like pattern; and smaller branches that divide in a dichotomous fashion to supply 1 to 2 separate cotyledons. Arterial anastomoses were not found between separate cotyledons in the examined placentas. Most cotyledons are supplied by 1 or 2 branches from a single arterial trunk. This type of branching resembles the islands of leaves on a bonsai tree, which finally gain their supply from 1 branch. 


\section{Measurements}

The lengths and diameters of the vessel segments were measured in the arteries of the human placenta and the arteries and veins of the bovine placentas. The histologic samples of these arteries, as well as samples from various segments of human cerebral vessels taken from cadaver heads, were processed with hematoxylin and eosin, reticulin, and elastin staining. The vessel wall thickness and the amount of reticular and elastic fibers were calculated from microscopic images (Image J 1.48v software, $\mathrm{NIH}$ ) and compared between the human $\mathrm{A}_{1}-\mathrm{A}_{4}$ segments of the anterior cerebral artery (ACA), $\mathrm{M}_{1}-\mathrm{M}_{4}$ segments of the middle cerebral artery (MCA), $\mathrm{P}_{1}-\mathrm{P}_{3}$ segments of the posterior cerebral artery, $\mathrm{C}_{1}$ segment of the internal carotid artery (ICA), superficial temporal artery (STA), radial artery (RA), human placental arteries, and bovine placental arteries and veins. The adventitia had the most inconstant thickness among all studied vessels and is usually removed before anastomosis; therefore, the intima-media thickness was measured instead of the total thickness of the vessel wall.

\section{Microvascular Training Models}

The 2 umbilical arteries and the vein of each human placental cord were cannulated and incorporated into a continuous colored normal saline flow circuit under a pressure of 100 to $180 \mathrm{~mm} \mathrm{Hg}$, which was generated by a compressive air bag. The human placenta was placed into a skull with a previously created bone window in order to provide a realistic operative situation with the depth and restrictions of a craniotomy (Fig. 1). The fetal surface vessels of the placentas were oriented to be accessible under the craniotomy window. Vessels with diameters of 0.8 to $1.5 \mathrm{~mm}$ and 1.0 to $2.0 \mathrm{~mm}$ were measured and used to simulate the human MCA and STA, respectively. Bovine placental vessel segments of 8.0 to $9.0 \mathrm{~mm}$ and 2.0 to 3.0 $\mathrm{mm}$ in diameter were used for simulation of the human ICA and RA, respectively (Fig. 2).

The following techniques and anastomoses were reviewed and performed: in situ end-to-side, end-to-end, and side-to-side bypasses, and a bypass with a long interposition graft. The latter was performed between a large bovine vein and a human placental artery, similar to an ICA-RA-MCA bypass. These anastomoses were reproduced to show technical nuances for training. The equipment used in the study consisted of surgical scissors, microsurgical forceps, needle holder, microscissors, 10-0 noncutting sutures, temporary microvascular clips, clip applier, Foley catheters, intravenous line, plastic bottle for infusion, compressive bag with a manometer, dissection microscope, a sink with running water, and red dye.

\section{Participants}

The microvascular bypasses described above were performed on the placenta models by the 30 participants according to the training module. The participants were assigned to 1 of 2 groups: "trained," which included those who had previously completed comprehensive microsurgical training or had microvascular anastomosis surgical experience; or "untrained," which included those who were attending a microsurgical training course for the first time and neurosurgeons without experience in microvascular anastomosis.

\section{Face and Content Validity}

The end-to-side anastomosis technique is the most common and was chosen for our training module on the human placental vessels for validation purposes. This module was developed at the neurosurgical laboratories of the participating institutions and during a neurosurgical course on techniques for cerebral revascularization.

After completing the end-to-side anastomosis, participants completed a 6-question Bypass Participant Survey. Each question was answered by the participants on a scale from 1 to 20 according to the degree of agreement (low to high) with the statements provided. The first 3 questions evaluated face validity: the participants assessed the degree of actual task replication and difficulty in comparison with real surgery. The other questions evaluated content validity: the participants assessed the potential of

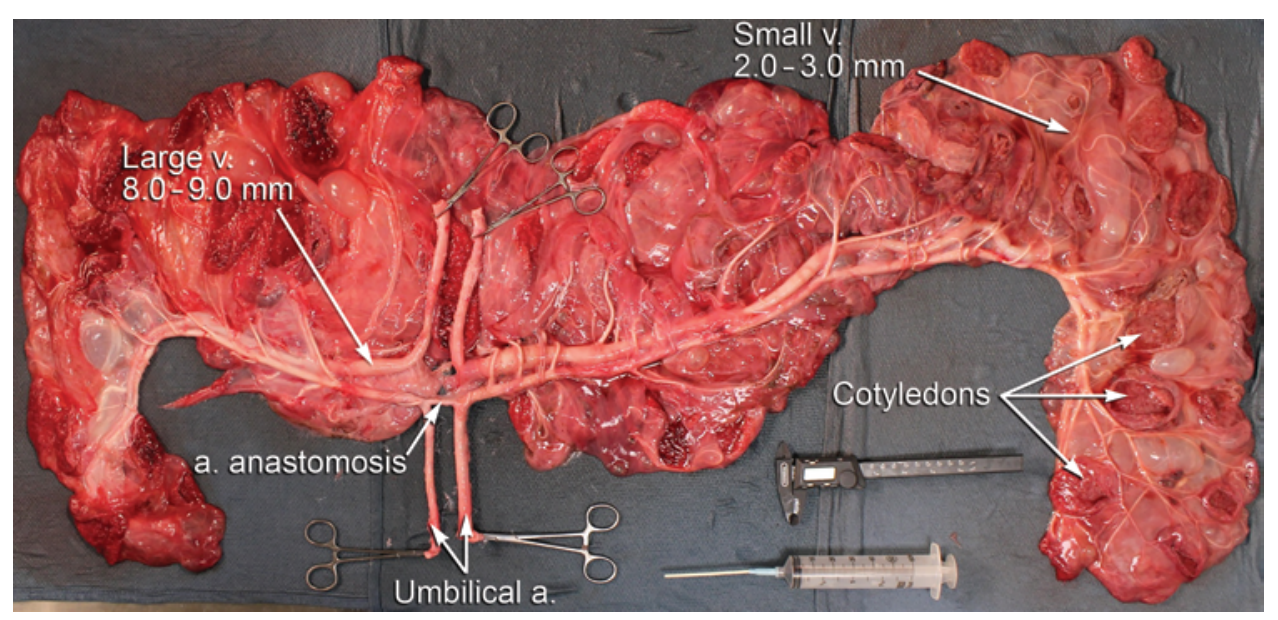

FIG. 2. Bovine placental vessels dissected to show numerous branches, which could be used as a training model. Umbilical vessel bifurcations and large veins were used to simulate the ICA. The small distal branches were used to simulate the RA. a. = artery/ arterial; $v$. = vein . 
the training tool to improve their microdissection and microinstrument handling skills and the likelihood that the skills obtained could be translated into improvements in real surgical performance.

\section{Construct Validity}

The overall performance of each participant was assessed using the Northwestern Objective Microanastomosis Assessment Tool (NOMAT) by fully trained neurosurgical fellows (E.B. and T.L.) who were familiar with the cerebrovascular techniques. ${ }^{10}$ To analyze construct validity, we divided participants into trained and untrained groups as described above.

\section{Statistical Analysis}

Statistical analysis was performed using Statistica 8.0. (StatSoft Inc.). The Mann-Whitney U-test was used for comparisons between the 2 participant groups and comparisons of vessel wall thicknesses and the amounts of reticular fibers between pairs of vessels. Differences were considered significant when $\mathrm{p}<0.05$. Logistic regression model analysis was applied to predict successful performance (and be assigned to the "trained" group or "untrained" group) based on the quantitative NOMAT score.

\section{Results}

\section{Anatomical and Histological Studies}

\section{Human Cerebral Arteries and RAs}

The monolayer of epithelial cells and internal elastic lamina was well visualized in the intimal layer of the cerebral arteries (Fig. 3). Characteristic intimal changes, such as smooth muscle cell proliferation and atheromatous plaques, were observed in all cerebral artery specimens. The media occupies up to $80 \%$ of the thickness of the vascular wall and includes various layers of smooth muscle cells, a small amount of elastic fibers, and a collagen framework. The elastic fibers of the media were not visualized in almost all distal cerebral vessels. The media of those vessels mostly contained reticular fibers that were interwoven in a 3D pattern, creating a mobile grid-like frame. Media thickness was the least variable parameter, demonstrating a clear tendency to decrease with a higher segment number of the cerebral vessel.

The media of the human RA was significantly thicker than the cerebral $(\mathrm{p}<0.01)$ and placental arteries $(\mathrm{p}<$ 0.01 ), but close to the thickness of the small bovine placental artery $(\mathrm{p}=0.05)$ (Figs. 4 and 5). The amount of reticular fibers in the media of all vessels had a directly positive correlation with media thickness (Spearman $\mathrm{R}=$ $0.54 ; \mathrm{p}<0.05)$. Vessels with more developed elastic properties, like the ICA and RA, had less dense reticular fibers than distal cerebral arteries.

\section{Human Placental Arteries}

The average length of the human placental arterial segments corresponded to the average length of the $\mathrm{M}_{2}$ and $\mathrm{M}_{4}$ segments of the cerebral arteries (Table 1). The diameters of the second-division segments approximated that of the $\mathrm{M}_{1}$ (range $2.7-4.9 \mathrm{~mm}$ ), ${ }^{33}$ petrous ICA (range
$3.8-5.6 \mathrm{~mm}$ ), ${ }^{3}$ and vertebral artery (range $2.5-4.0 \mathrm{~mm}$ ). The diameters of the third-division segments were close to those of the ACA (range 1.0-3.0 mm), ${ }^{34} \mathrm{M}_{2}-\mathrm{M}_{4}$ segments (range 0.8-3.5 mm), ${ }^{34}$ STA (range $1.0-2.7 \mathrm{~mm}$ ), ${ }^{27}$ posterior inferior cerebellar artery (PICA) (range 0.6-1.8 $\mathrm{mm}$ ) ${ }^{34}$ and maxillary artery (mean \pm standard deviation $2.8 \pm 0.1 \mathrm{~mm}){ }^{8}$

The media of the human placental arteries has a loose reticular framework and smooth muscle cells. In contrast to cerebral arteries, placental arteries showed the absence of internal elastic lamina and elastic fibers in the media of all studied samples when treated with elastin stain (Fig. 3). The significantly lower blood pressure in the placental arteries would not seem to require such a tissue layer, where the pressure is a maximum of $60-80 \mathrm{~mm} \mathrm{Hg}$ during the final weeks of pregnancy. The adventitial layer of these vessels was loose, highly variable in size, and continuous with chorion at the inferior side of the artery. During a real anastomosis, it is important to remove loose adventitial tissues, especially from the STA. Similarly, the removal of the adventitial layer from the placental artery is necessary to maintain vessel walls that are clean and free of debris. Because the placental artery wall thickness was highly variable, it was not statistically significantly different from the wall thickness of the cerebral arteries ( $p>0.05)$ (Fig. 4). The wall thickness of a 1-mm human placental artery was comparable to that of the $\mathrm{M}_{4}$ segment $(\mathrm{p}=0.15)$, but it contained significantly fewer reticular fibers $(\mathrm{p}<0.01$; Fig. 4). The wall thickness and amount of reticular fibers in a $1.8-\mathrm{mm}$ placental artery differed significantly from the STA ( $<<0.01$; Fig. 4); however, such differences are not substantial in practice.

\section{Bovine Placental Arteries and Veins}

Bovine placenta contains a plethora of arterial and venous segments with diverse diameters, from which 3 groups of segments can be dissected: large, medium, and small diameters. Long (range 5.0-40.0 cm) small-diameter segments are subterminal arteries that feed cotyledons and have few side branches. For the large bovine vessels that were studied, the diameters of the placental venous segments (range $8.0-9.0 \mathrm{~mm}$ ) and the long small-diameter distal branches (range 2.0-3.0 mm) were close in diameter to those of the human cervical ICA (range 3.2-9.8 mm) and RA (range 2.0-3.0 mm), respectively, and wall thickness was comparable ( $\mathrm{p}=0.05$ and $\mathrm{p}=0.2$, respectively) (Figs. 5 left, 3C, and 3D). However, there were more reticular fibers in the corresponding bovine placental veins than in the ICA or RA ( $p=0.01$ and $p<0.01$, respectively) (Fig. 5 right).

The media was composed of circularly oriented muscle fibers in the outer layers, longitudinally oriented muscle fibers in the inner layers, and a mesh of reticular fibers. Bovine placental arteries had more reticular fibers than bovine placental veins. This structure makes the wall hard, stiff, and difficult to puncture with a needle.

\section{Training Exercises}

\section{End-to-Side Bypass Model}

The end-to-side bypass model was intended to replicate 

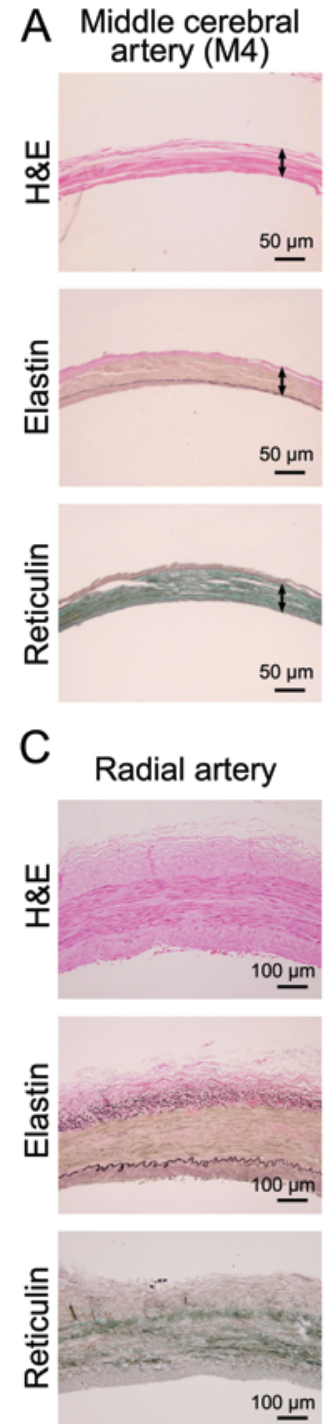
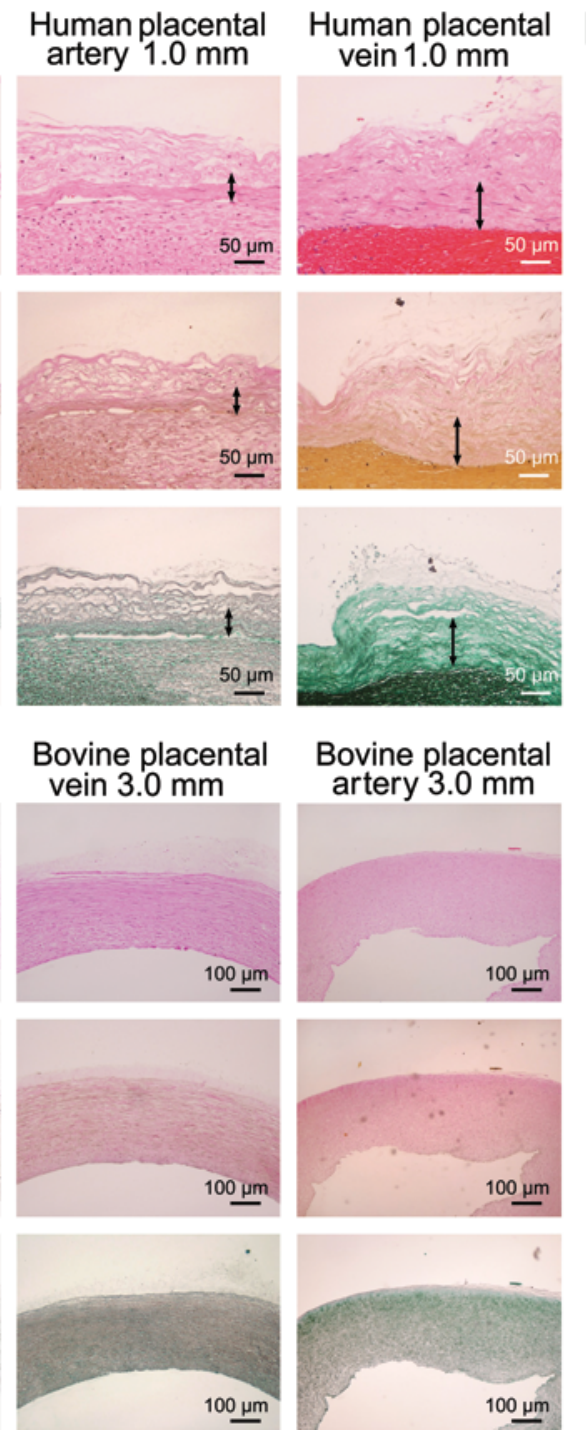
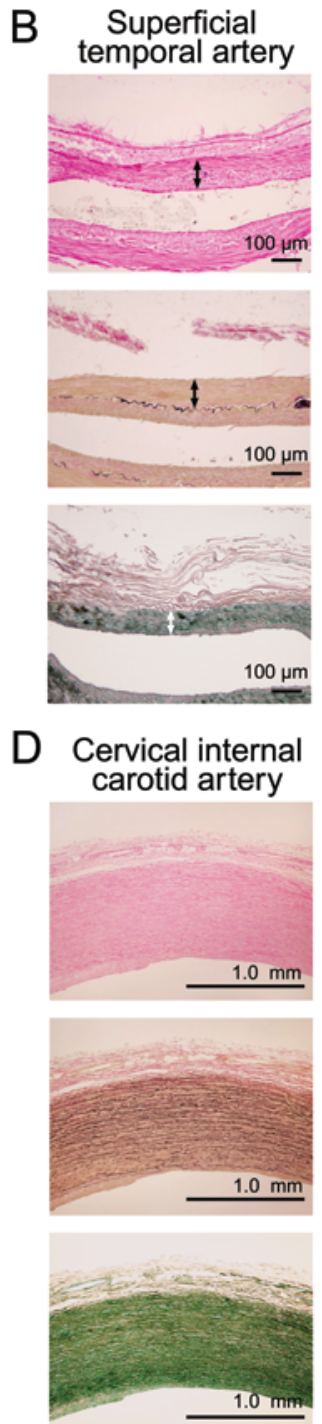
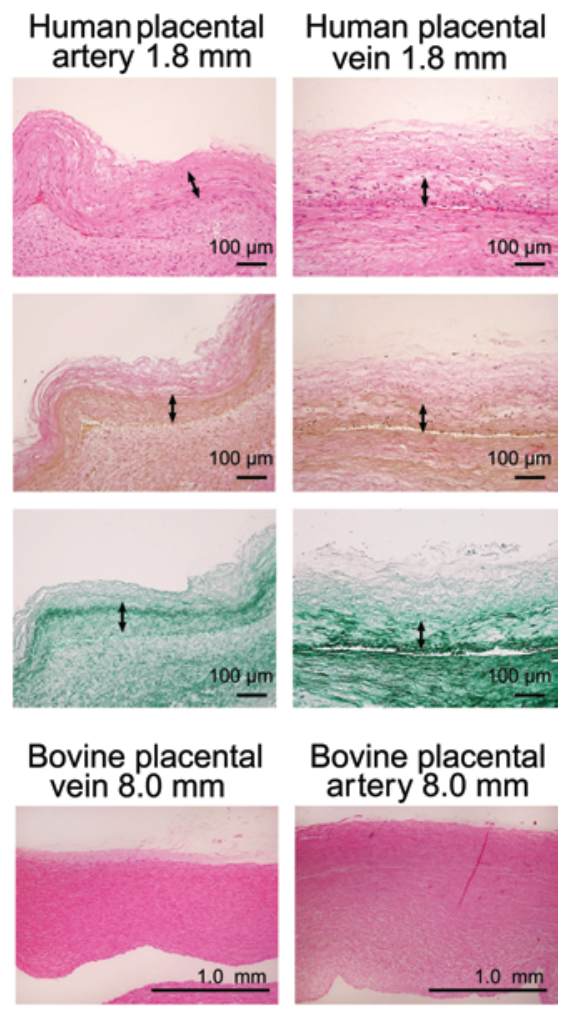

Bovine placental artery $8.0 \mathrm{~mm}$
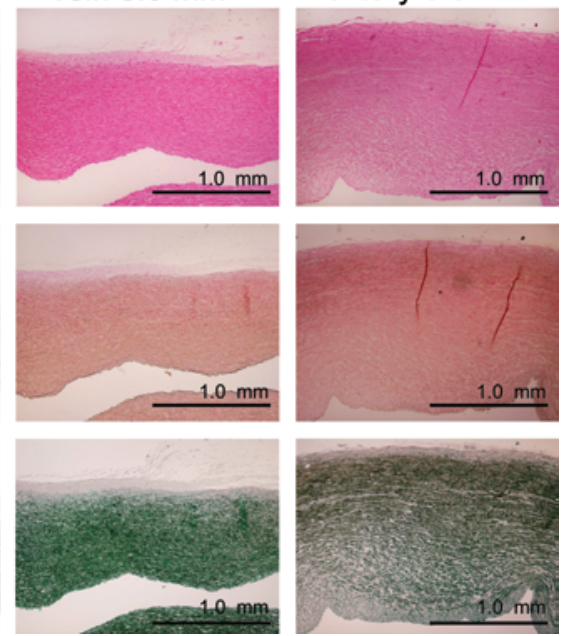

FIG. 3. Histological comparison of the arteries used in cerebral bypass with the human and bovine placental vessels of various diameters used for simulation. The arrows represent the thickness of the intima-media complex. $A$ : The $M_{4}$ segment wall of the MCA is slightly thicker than a 1-mm human placental artery, containing a loose adventitial layer. Human placental veins are thicker and the fibers are arranged more loosely than those of the MCA. Note that compared to the MCA, the bottom walls of the human placental artery and vein are significantly thicker, have a looser fiber orientation, and continue into the chorionic plate of the placenta without clear demarcation. Human placental vessels lack an internal elastic membrane. B: The STA has a loose adventitial layer, similar to the human placental artery and vein. The thickness of the intima-media complex of $\sim 2$ mm in human placental arteries is closer to that of the STA than the thickness of the intima-media complex of a human placental vein of the same diameter. C: The RA is also covered with a thick layer of loose adventitial tissue that has to be removed before suturing. The bovine placental veins and arteries with corresponding diameters have the same intima-media thickness as the RA, but the bovine placental artery has more reticular fibers, which make the wall hard, stiff, and difficult to puncture with a needle. There are a few scattered elastic fibers in the media layer and a thin internal elastic layer in the innermost part of the bovine placental artery. Intimal thickening can be seen in the RA, representing senile and atherosclerosis-related changes. D: The cervical portion of the ICA has numerous elastic fibers in the media. The bovine placental artery and vein also have elastic fibers in the media. The intima-media thickness of the bovine placental artery with a corresponding diameter is much thicker than that of the bovine placental vein and ICA.

an extracranial-intracranial STA-MCA bypass. A human fetal-surface placental arterial segment of 4 to $5 \mathrm{~cm}$ in length and 1 to $2 \mathrm{~mm}$ in diameter, similar to the STA, and a second segment of 0.8 to $1.8 \mathrm{~mm}$ in diameter, similar to the MCA, were used for this model (Fig. 6A). Arteries with fewer branches are more suitable after dissection from adherent chorionic tissue using blunt-end microscis- sors. Any branching that could not be avoided was ligated. Methylene blue dye was applied to the anastomosing vessel sites to facilitate visualization of the vessel wall, especially the intima and adventitial debris. Microscissors were used to perform a "fish-mouth" arteriotomy on the donor vessel by making an angled cut in the vessel end with enlargement by cutting the same distance parallel to 

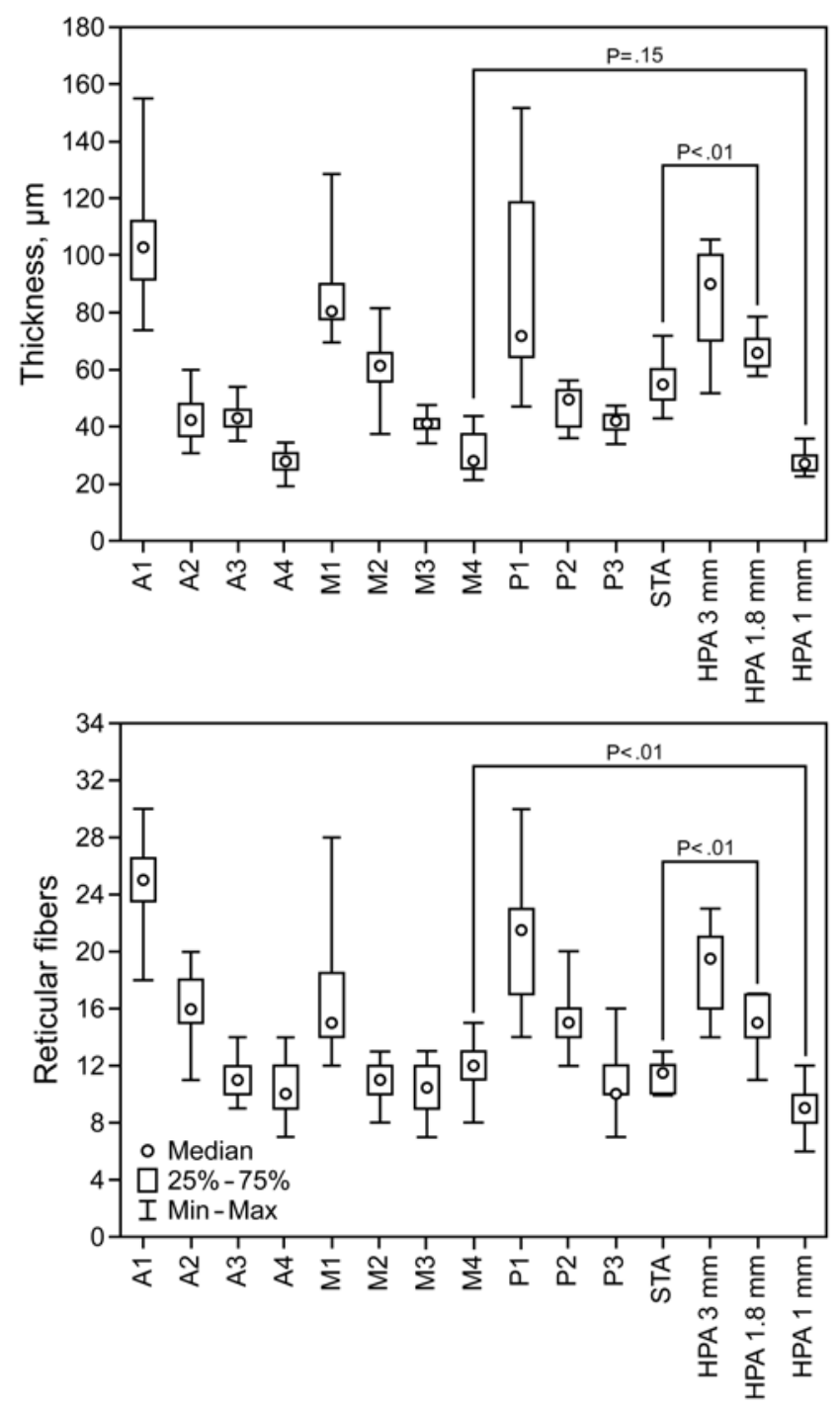

FIG. 4. Comparison of vessel wall thickness (upper) and number of reticular fibers (lower) in human cerebral arteries $\left(A_{1}-A_{4}, M_{1}-M_{4}\right.$, and $\mathrm{P}_{1}-\mathrm{P}_{3}$ ), STA, and human placental arteries (HPAs) of varying diameters. The vessel wall thickness of a 1-mm diameter human placental artery is slightly thinner (not statistically significant) than the corresponding $\mathrm{M}_{4}$ segment and carries a comparable, although statistically significantly different, amount of reticular fibers in the wall on cross-section. (The median [min-max] number of reticular fibers on cross-section is 9 [6-12] for human placental artery vs 12 [8-15] for $\mathrm{M}_{4 .}$.) The 1.8-mm diameter human placental artery most closely approximates the STA, although the thickness and amount of reticular fibers is statistically significantly different ( $p<0.01$ and $p<0.01$, respectively); however, in practice such differences are not apparent during surgical procedures. The human placental arteries of 3-mm and 1.8-mm diameters are slightly but statistically significantly, thicker than the corresponding cerebral arteries of the same diameter, and human placental arteries carry a slightly, but significantly smaller number of reticular fibers than the corresponding cerebral arteries of the same diameter (as described in Table 1).

the vessel axis. After the recipient segment was clamped, a straight arteriotomy was made using an insulin syringe needle followed by enlargement using straight microscissors. For a running technique, 2 noncutting 10-0 nylon microsutures were used to secure the posterior (heel) and anterior (toe) ends of the arteriotomies. Attention was paid to start suturing from the outside to inside of the vessel wall so that the knot would be formed outside the lumen. After the knot was secured, the threads were not cut and remained intact in order to secure the vessel to the surrounding tissues. Usually, the vessels were oriented in the direction of the "STA" from the top of the surgical field, then turned parallel to the "MCA" segment. The difficult side of the anastomosis (which is the left aspect in vertically oriented vessels or the top aspect in horizontally oriented vessels) was sutured first, starting from the distant end of the vessel wall toward the nearer one, or from right to left, so that the running suture loops would not compromise the workspace for the off-hand forceps that provided counter-pressure on the vessel wall (Fig. 7). The running suture was tied with the interrupted suture, then the other running suture for the opposite wall was started with the thread from the second interrupted suture. Alternatively, a series of interrupted sutures could be placed at either edge of the arteriotomy (Fig. 6B). After finishing the anastomosis and removing the clamps, we could observe the flow, and any faults or errors of the suturing appeared as a tortuosity, stenosis, or major leak.

\section{Side-to-Side and End-to-End Bypass Models}

The side-to-side bypass model was intended to replicate a PICA-PICA or ACA-ACA anastomosis, while the end-to-end bypass model was intended to replicate an MCA-MCA reanastomosis. Only fetal-surface arteries of the human placenta were used in these models. Two arteries were dissected to simulate the feeding and receptor artery (the fewer the branches, the better). Locating 2 vessels near each other may shorten the dissection time.

For the side-to-side bypass, 2 close vessels were selected or a single long vessel was dissected that could be looped back onto itself. The entire vascular surface was gently dissected and cleaned from adventitial tissue. Two temporary clips were placed to bring the vessels close together and occlude flow. A pair of separate microclips could be used to stabilize each vessel and avoid excess tension. The vessel orientation was horizontal for the "ACA-ACA" bypass and vertical for "PICA-PICA" bypass simulation. A fine syringe needle and microscissors were used to perform parallel arteriotomies with lengths approximately equal to or more than double the diameter of the vessel. A noncutting 10-0 nylon microsuture was used to close a single distant vertex of the arteriotomies with 1 interrupted stitch. Passing the needle in a manner such that the knot remained outside of the joined lumen was a key maneuver. The needle was then passed between the vessels and punctured the vessel wall from outside to inside. Subsequently, a running suture secured the opposite edges of the arteriotomies. Close approximation of the edges allowed the simultaneous passing of the needle through the 2 arterial walls and significantly minimized the time required for the procedure. The running loops were then securely tightened one after another with the 2 forceps, and a knot was placed outside. This knot was made between the needle end of the suture and the preceding external suture loop. The other technique entailed both poles of the arteriotomies connected by separate microsutures with the 

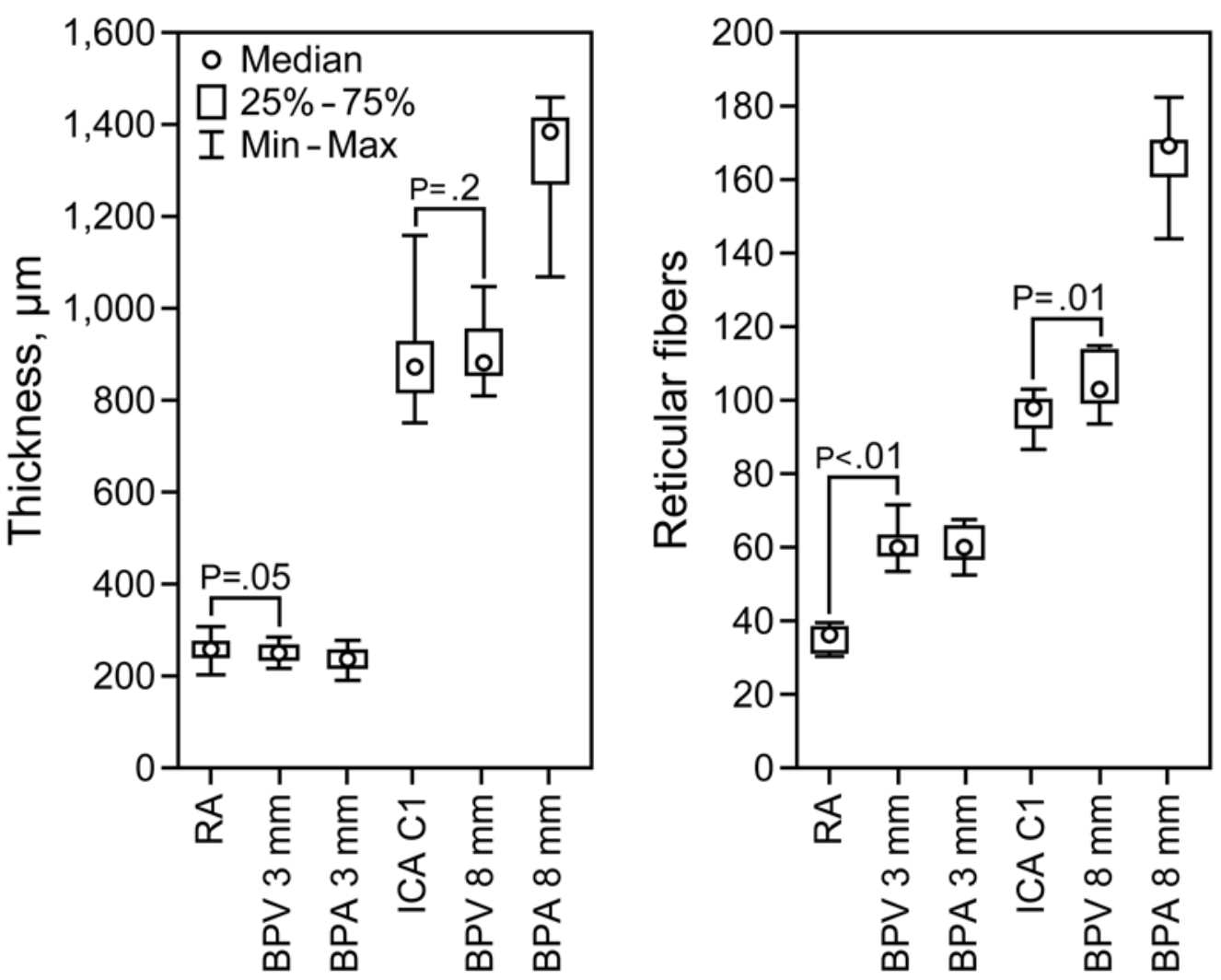

FIG. 5. Comparison of vessel wall thickness (left) and number of reticular fibers (right) of human RA, $C_{1}$ segment of the ICA, and bovine placental vein (BPV) and artery (BPA).

running suture starting from one to another and tied. The suture run was then continued with the same or a second suture. The suture run should be evenly spaced and ended with a knot at the apex of the vessels (Fig. 8A and B).

For the end-to-end bypass model, a single surface artery was gently dissected and cleaned. Two temporary clips were placed to occlude flow, leaving 5 to $10 \mathrm{~mm}$ of space between them. Next, microscissors were used to cut the vessel sharply between the clips. One interrupted stitch was placed to connect the inferior surfaces of the anastomosis between 2 points opposite one another, using the technique described above. Then, wide continuous needle and suture passes were placed to connect the superior surfaces of the vessels, without tightening the suture loops. When complete, the apex of each loop was cut to yield 4 straight lines of sutures through the superior aspects of the vessels that were separately tied as interrupted stitches.
Next, the clips were flipped to expose the inferior vascular surfaces, which were then secured in a similar manner (Fig. 9).

\section{Model of Bypass With Interposition Graft}

The bypass model using an interposition graft was intended to be similar to an ICA-RA-MCA bypass. A bovine placental vein of 2.0 to $3.0 \mathrm{~mm}$ in diameter and $20 \mathrm{~cm}$ in length and a second vein of 8.0 to $9.0 \mathrm{~mm}$ in diameter and $10 \mathrm{~cm}$ in length were dissected to simulate the RA and ICA, respectively (Fig. 10). The larger vein was connected to a pressurized flow and set up near the skull and a human placental artery was prepared and placed inside the skull to represent the MCA (Fig. 1). One end of the "RA" was anastomosed to the side of "MCA" and another to the "ICA" separately. Anastomosis techniques similar to those previously described in the STA-MCA model were

TABLE 1. Diameters and lengths of the arterial segments found on the fetal surface of the human placentas and comparison with the vessels used in bypass surgeries

\begin{tabular}{cccc}
\hline $\begin{array}{c}\text { Artery of the Fetal Surface of } \\
\text { Human Placenta }\end{array}$ & Mean Length \pm SD (range) & Mean Diameter \pm SD (range) ${ }^{*}$ & $\begin{array}{c}\text { Segments of the Cranial Arteries \& Grafts } \\
\text { w/ Diameters Similar to HPAs }\end{array}$ \\
\hline 1st division & $28.8 \pm 9.9(15.0-48.0)$ & $6.5 \pm 1.4(3.00-9.00)$ & NA \\
\hline 2nd division & $35.9 \pm 15.3(4.0-75.0)$ & $3.4 \pm 0.7(2.00-5.00)$ & M $_{1}$, petrous ICA, VA \\
\hline 3rd division & $29.9 \pm 10(15.0-64.0)$ & $1.7 \pm 0.4(0.80-3.00)$ & ACA, M $_{2}, M_{3}, M_{4}$, STA, PICA, MA \\
\hline
\end{tabular}

HPA = human placental artery; MA = maxillary artery; NA = not applicable.

* Values are shown in millimeters. 

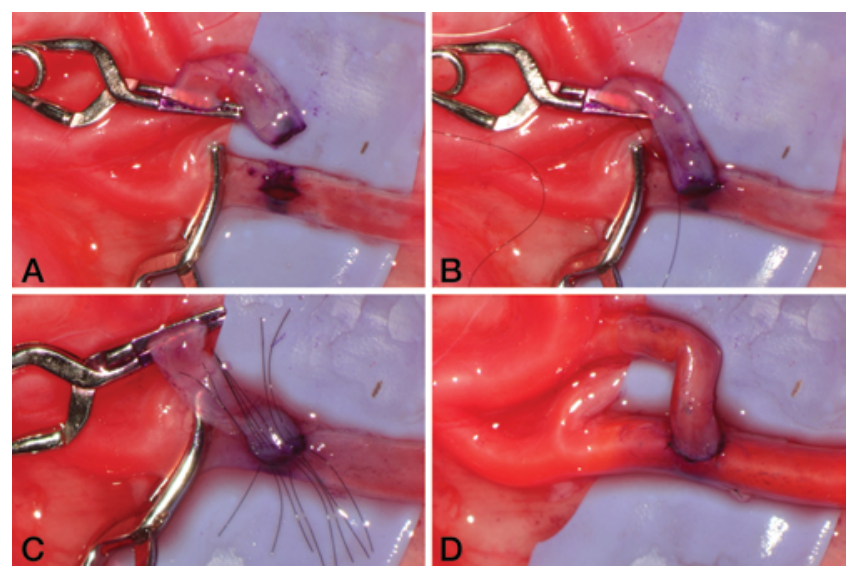

FIG. 6. End-to-side anastomosis with interrupted sutures. A: Arteriotomies of corresponding length are performed on the donor and recipient vessels and stained with blue dye to increase visibility. B: A noncutting 10-0 nylon microsuture is used to secure the anterior (toe) and posterior (heel) ends of the arteries. C: A number of interrupted sutures are placed at the side of the anastomosis. D: The complete anastomosis is inspected after flow is restored to assess flow and leaks.

employed (Fig. 11). This anastomosis was unique in terms of the thickness of the graft and of the ICA model; for this reason, $8-0$ or 6-0 sutures were used.

\section{Validity Studies}

Seven resident neurosurgeons and 10 staff-level neurosurgeons composed the group of trained participants $(\mathrm{n}=$ 17 ), whereas 10 medical students and 3 neurosurgery residents composed the group of untrained participants $(\mathrm{n}=$ 13). All 30 participants finished at least 1 bypass operation on a placental bypass model and then completed the posttraining survey.

\section{Face and Content Validity}

With scores ranging from 1 to 20 , most of the trained
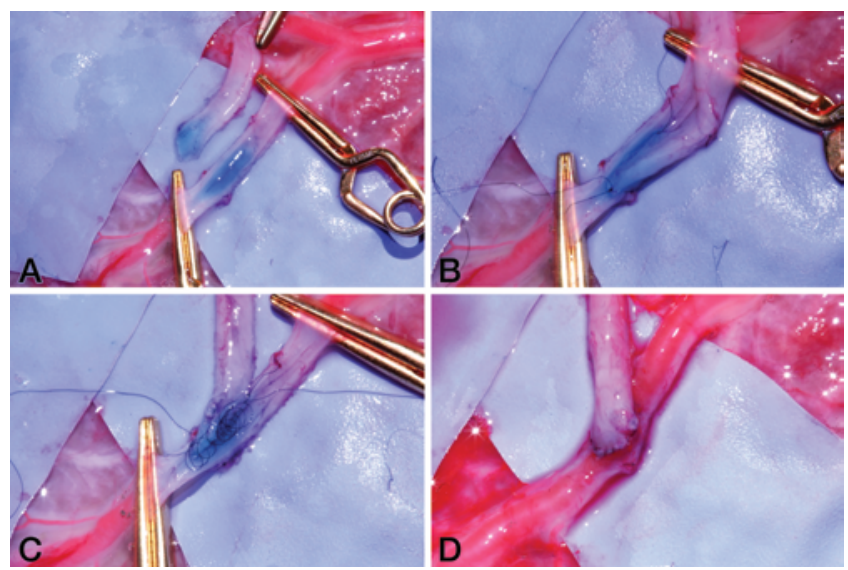

FIG. 7. End-to-side anastomosis with running suture. A: The donor vessel is tailored in a fish-mouth fashion and an arteriotomy of corresponding length is performed on the recipient vessel. B: A noncutting 10-0 nylon microsuture is used to secure the anterior (toe) and posterior (heel) ends of the arteries. C: Running individual stitches are placed on one side. D: A completed anastomosis after flow restoration.
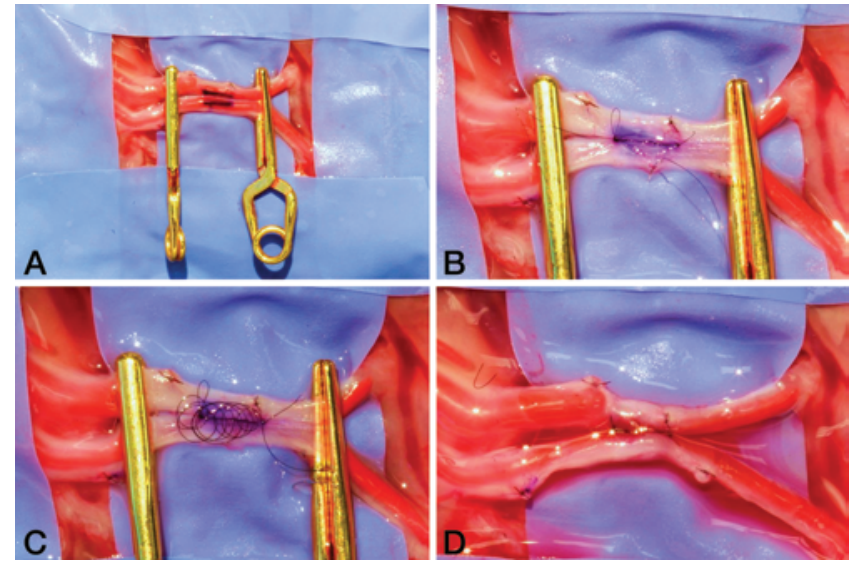

FIG. 8. Side-to-side anastomosis with running suture. A: The vessels are aligned parallel to each other and a planning incision is marked with dye. B: A running stitch secures the inferior edges of the vessels. C: The loops of the running suture continue along the superior edge of the anastomosis. D: Flow restoration shows no significant leakage.

(16 of 17; 94\%) and untrained (12 of 13; 92\%) participants (total 28 of 30; 93\%) scored the ability of the training model to replicate real bypass surgery within the interval from "more than somewhat" (score 13) to "very well" (score 20), and 1 of $17(6 \%)$ of the trained and 1 of $13(8 \%)$ of the
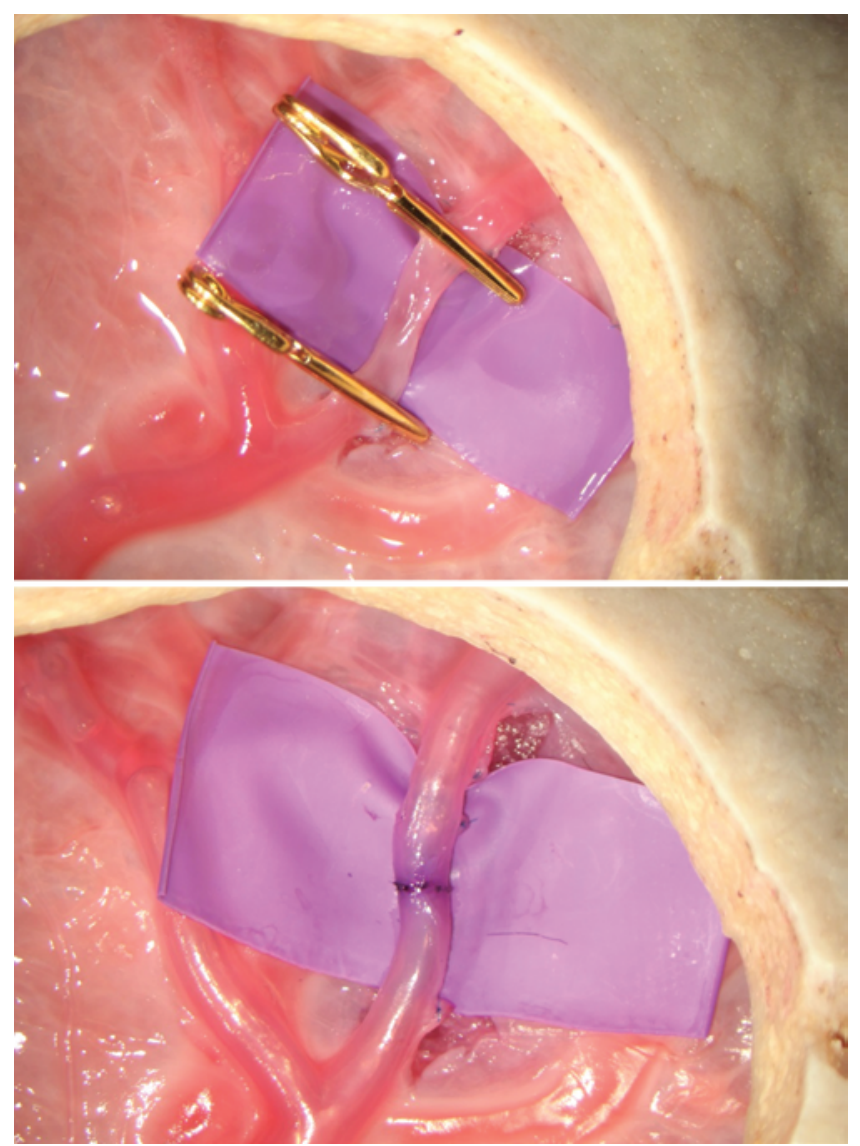

FIG. 9. End-to-end microanastomosis with interrupted sutures. Upper: Two temporary clips are placed on the dissected vessel to occlude flow, leaving $1.5 \mathrm{~cm}$ of space. Lower: Restored flow shows no leakage. 


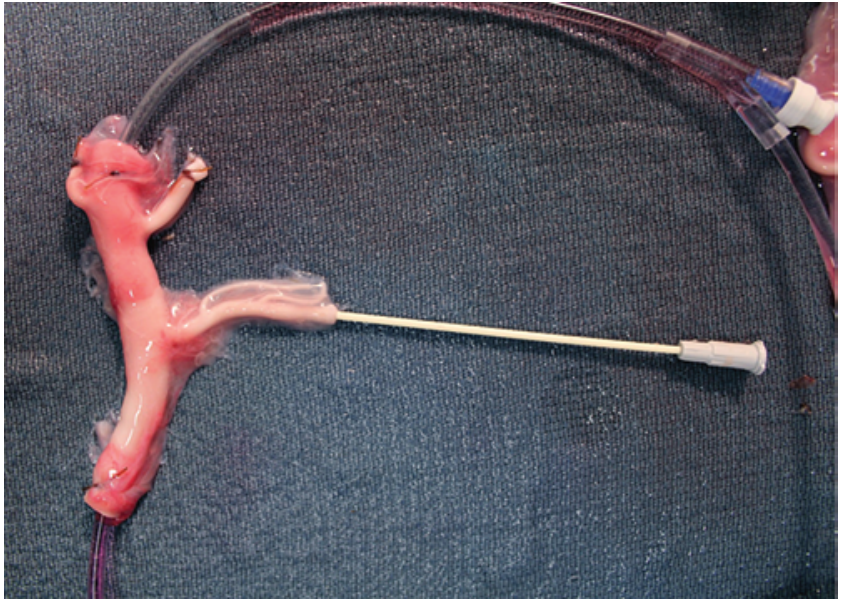

FIG. 10. Pressurized bovine placental vein simulating bifurcation of the carotid artery.

untrained (total 2 of 30; 7\%) participants scored the training as "somewhat" replicating real surgery (a score within the interval of 8-12). Differences in scores between the 2 groups show a trend toward significance $(\mathrm{p}=0.06)$. Most participants in the trained (16 of 17; 94\%) and untrained (11 of 13;85\%) groups (total 27 of 30; 90\%) also estimated the difficulty of the task as nearly "the same" (score interval 5-15) as real surgery. The differences between the groups were significant $(\mathrm{p}=0.03)$. Taking into account only the responses from trained participants, the values of $94 \%$ for both questions correspond to a high face validity value for the simulation model (Fig. 12). There were no significant differences in the answers between groups for the question of how successful the participant was in accomplishing the task $(\mathrm{p}=0.38)$, which contradicts the results obtained by the objective measurements (see construct validity). With regard to questions about the ability of the model to improve microsurgical techniques and instrument handling, 30 of $30(100 \%)$ participants answered positively (within the interval of 15-20). In addition, 30 of 30 participants considered the model to be able to improve surgical technique when the skills were applied to patients (scores within the interval of 15-20). There were no significant differences between the groups for the 3 questions related to content validity (Fig. 13) $(p=0.99, p=0.77$, and $\mathrm{p}=0.65$, respectively).

\section{Construct Validity}

In a comparative analysis of the performance scores between the 2 groups, the mean NOMAT score of the untrained group $(37.2 \pm 7.0)$ was statistically significantly lower than the mean NOMAT score of the trained group $(62.7 \pm 6.1 ; \mathrm{p}<0.01)$. Logistic regression analysis indicated a $50 \%$ probability of being allocated to either group when a participant's NOMAT score was 50 points (Fig. 14).

\section{Discussion}

\section{Importance of Appropriate Simulation Tools}

Since the introduction of endovascular technologies, more and more patients with aneurysms who were pre-
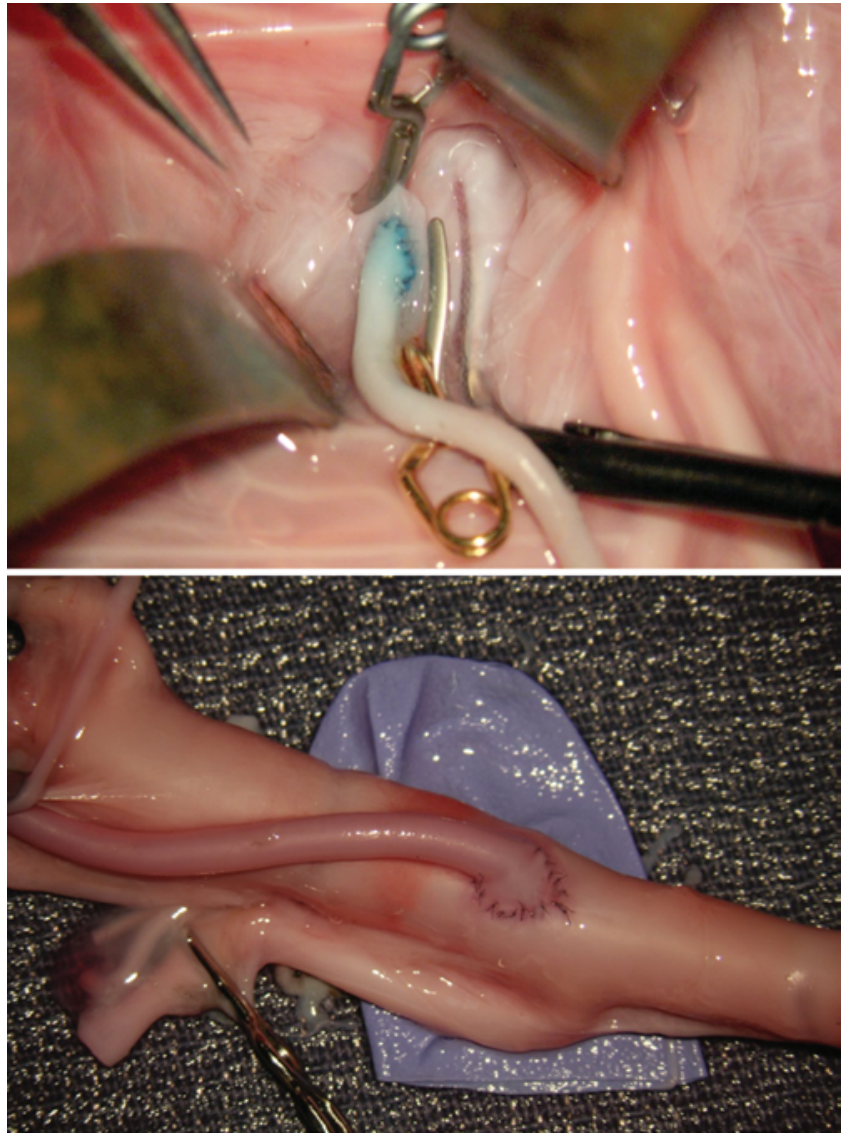

FIG. 11. Bypass with an interposition graft. Upper: Completed distal anastomosis between the vascular graft end and human placental artery side (similar to the RA-STA anastomosis). Lower: Completed proximal anastomosis between the vascular graft end (small-diameter long bovine placental vein) and side of the large bovine placental vein (similar to RA-ICA anastomosis).

viously considered for open surgery are now successfully treated by coiling and stenting of their aneurysms. Although advances in endovascular techniques have decreased the number of open surgeries for intracranial aneurysms, bypass surgery is still a critically valuable tool in the treatment of complex aneurysms. In addition, extracranial-intracranial bypass continues to be a main treatment for moyamoya disease, which has a high prevalence in select populations. Thus, it is crucial for neurosurgeons to practice microsurgical anastomosis in order to maintain mastery of the technique. ${ }^{23}$ For the neurosurgeon, bypass simulation models give important tactile feedback necessary for rehearsing fine anastomosis techniques. Live animal models provide the most realistic method for microvascular anastomosis training with pulsatile blood flow, natural viscosity, and coagulation; ${ }^{1}$ however, institutional protocols, expenses, and increasingly strict regulations regarding animal welfare, appropriate shelter, and surgical management impose significant but necessary constraints and economic and ethical issues regarding the use of live animal models.

Chicken and turkey wing microanastomosis models and silicone microtubing (and other nonbiological materi- 
How do you think the model replicates actual cerebral bypass surgery?

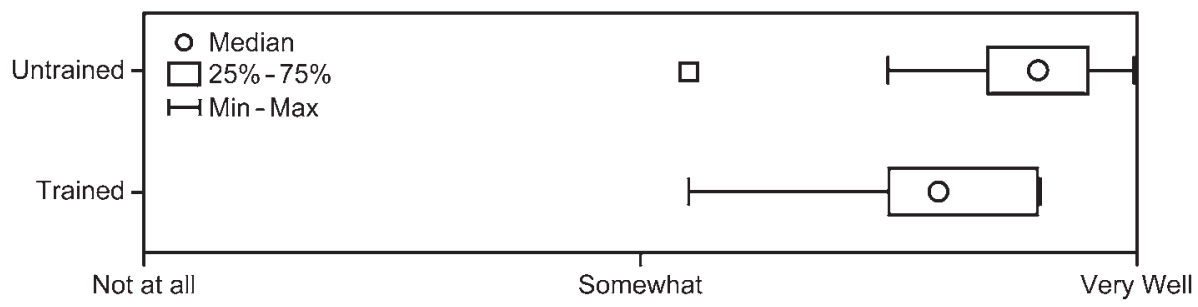

How difficult was the task compared to real surgery?

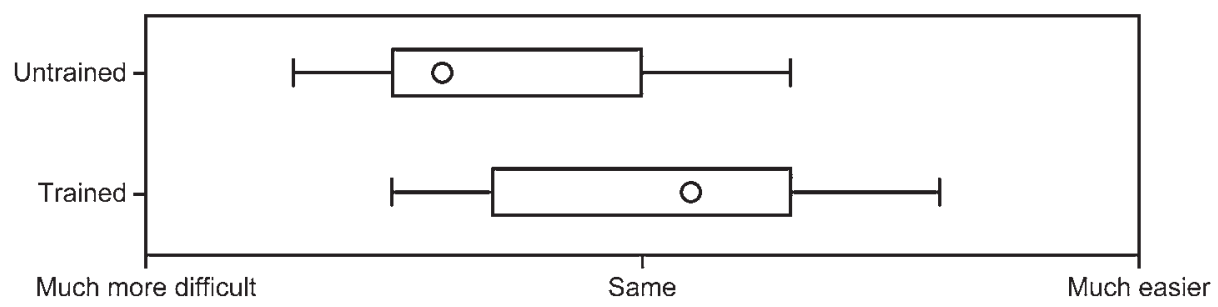

How successful were you in accomplishing the task?

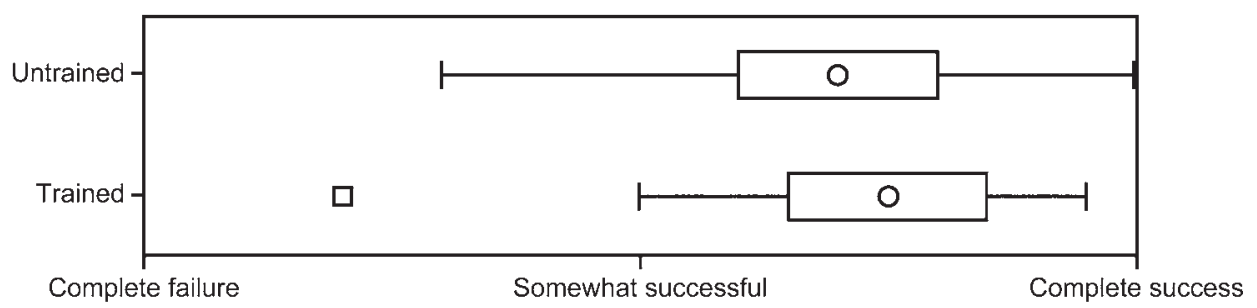

FIG. 12. Face validity of the bypass model evaluated by untrained and trained participants. $A$ trend was found for the first question $(p=0.06)$ in the answers between the 2 groups and a statistically significant difference was found for the second question $(p=$ $0.04)$. The differences in the scores for the third question were not significantly different between the 2 groups $(p=0.38)$.

als) are inexpensive, readily available, and allow practice anywhere. ${ }^{1}$ However, a limitation of these models is the less-than-ideal similarity of the tissues when compared with cerebral vessels. Small vessel diameters and the fact that the wings suffer from freezing artifacts after thawing often create difficulties with the use of poultry wing brachial arteries for practice. The median vessel diameter in poultry brachial vessels is just over $1 \mathrm{~mm}$ with a standard deviation of $23 \%$. Some of the chicken wing brachial arteries have been measured to be as small as $0.6 \mathrm{~mm}{ }^{1}$

Recently, we found that vessels from fresh human and bovine placentas are excellent tissue models. The fetal surface of a human placenta provides enough material for more than a dozen microsurgical anastomoses. One bovine placenta provides an average of 6 large bifurcations for carotid surgery simulations and more than enough smaller vessels for microanastomosis training. Although human placenta was proposed for microanastomosis training in 1979 by Goldstein, ${ }^{11}$ mentioned in neurosurgical literature by Ayoubi et al. in $1992^{2}$ and Romero et al. in $2008,{ }^{28}$ and recently reported as a substrate for producing models of arterial aneurysms, ${ }^{20,25}$ the use of bovine placental vessels as a model for microvascular training and simulation of bypass with interposition grafts similar to ICA-vascular graft-MCA bypass has not been reported.
We report here on the first known validation study for a model of microvascular anastomosis training using human placental vessels. We believe there is no doubt that microvascular techniques should be mastered in the laboratory. However, each teaching neurosurgical department has unique circumstances that make some models more practical and easy to accommodate in training curricula or off-the-job training. This is why the diversity of training models is so important, and detailed descriptions of such models may be helpful for those neurosurgeons who seek to master microvascular surgical techniques.

\section{Use of Placental Vessels as a Bypass Training Tool}

To practice various bypass types on placental vessels, one should dissect arteries with an appropriate diameter and sufficient length. Vessel segment length is particularly important for a donor vessel. We found that large placentas and placentas with lateral umbilical cord attachment have longer arterial segments on their fetal surfaces compared to small placentas and placentas with central umbilical cord attachment. Separation of the vessels that are immersed in the chorionic membrane is more difficult than separating those vessels that lay on the surface and are fused with the chorionic membrane only at the bottom. Some first-division arteries, most second-division 
Do you think practice on this model could help to improve microsurgical technique?

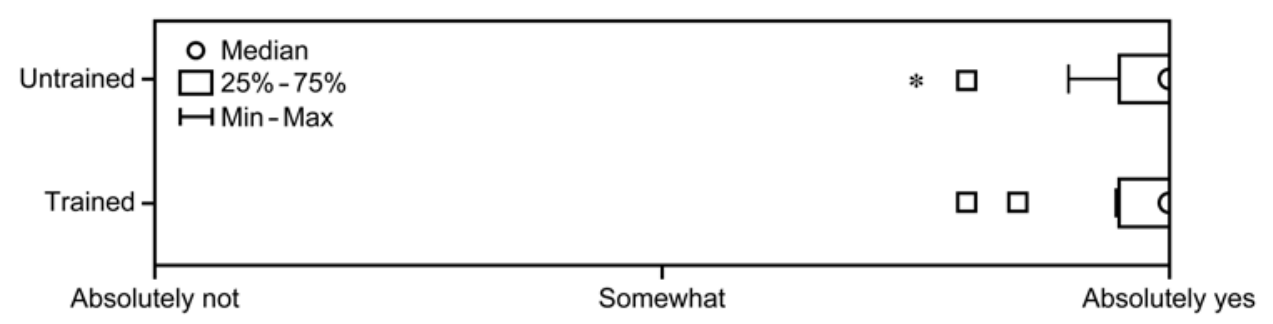

Do you think practice on this model could help to improve skills in handling microsurgical equipment?

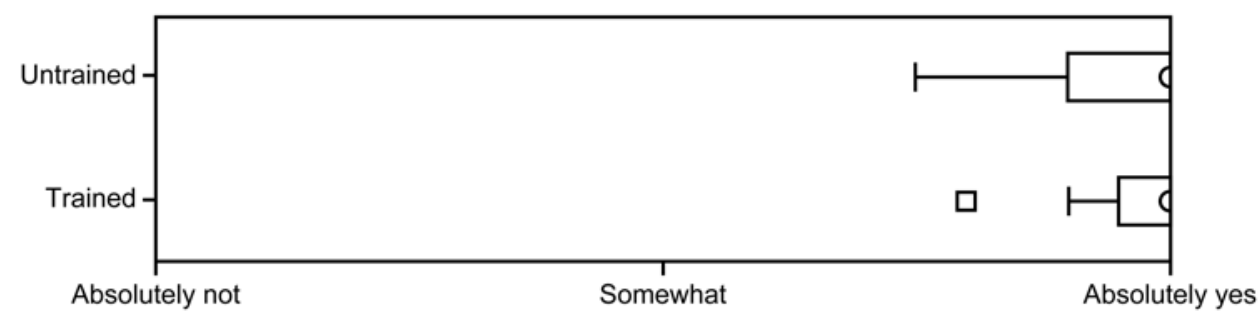

Do you think practice on this model will improve surgical technique when skills are applied to patients?

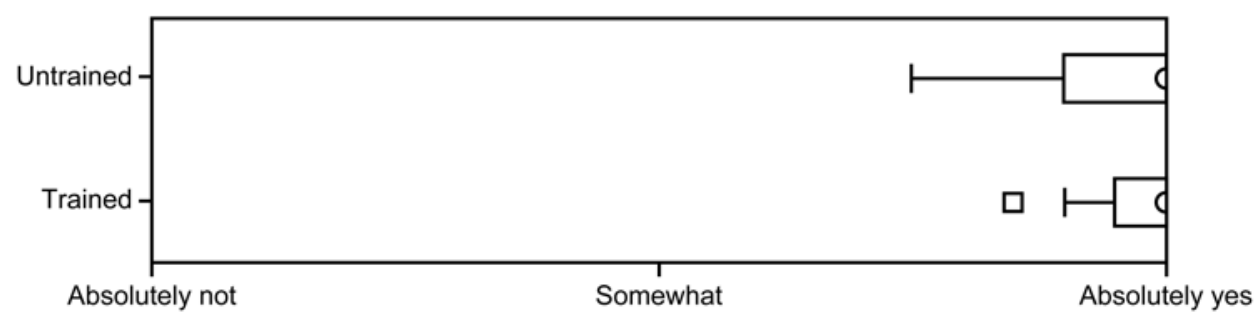

FIG. 13. Content validity of the bypass model evaluated by untrained and trained participants. The differences in the answer scores between 2 groups were not significant ( $p=0.99$ [top], $p=0.77$ [middle], and $p=0.65$ [bottom]). The asterisk represents an extreme value.

arteries, and almost all third-division arteries run above the chorionic layer and are bound with this layer only by their inferior vessel wall. Branching of the first- and second-division arteries usually occurs consecutively, less often dichotomously, or even more rarely in a trifurcated pattern. These branching patterns resemble the regions of the cerebral arteries. Third-division arteries travel on the chorionic layer and then turn deep into the placenta where they reach cotyledons. The diameter of a segmental artery is always less than its corresponding vein. Typically, the diameters of the umbilical arteries and arterial branches of the first order are not equal, thereby forming asymmetrical basins connected by the natural anastomosis at the root of the umbilical cord.

Human placental arteries have wall thicknesses, amounts of connective tissue fibers, and diameters that are similar to those in the human brain. In our study, human placenta provided sufficient lengths of arterial segments (diameter range $0.8-9.0 \mathrm{~mm}$ ) and covered all surgically relevant sizes of cranial vessels. ${ }^{16}$ Bovine placental veins provided a diameter range from 2 to $20 \mathrm{~mm}$, which covered all surgically relevant sizes of carotid arteries and RA grafts. ${ }^{16}$ Important differences between the placental and cerebral arteries include the absence of an internal elastic lamina and the presence of a thick base at the inferior aspect of the placental vessel where it attaches to the chorionic membrane. Nevertheless, these differences did not prevent us from reproducing the same anastomotic techniques as applied during human cerebral microvascular bypass procedures. Three different types of bypass techniques were performed on placenta models. All participants were able to finish bypass training on the model, including vessel dissection and anastomosis. For preparation of the model for an exercise, pressurized flow with colored normal saline solution was found to be of significant value because it allowed the trainee to encounter "bleeding" if a vessel was damaged, practice hemostasis with bipolar coagulation or ligation, and estimate flow through the anastomosis.

In this study, bovine placenta was not used as a substrate in the validity testing because of structural differences between bovine and human cerebral vessels and because of methodological requirements for a stable and reproducible model for all participants. However, bovine placenta was used as a convenient tissue for rehearsal and for creating models of larger vessel bypasses. Bovine placenta is not a human biological hazard and does not require institutional 


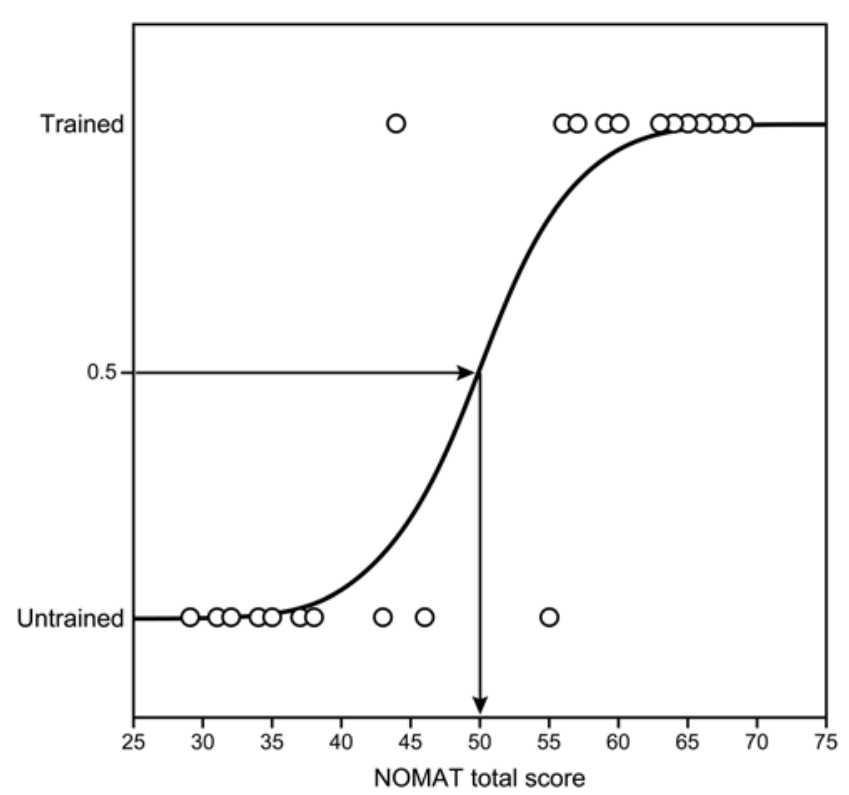

FIG. 14. Logistic regression analysis curve of the probability to be allocated in either the untrained or trained group, depending on the total NOMAT score.

review board or Institutional Animal Care and Use Committee approval to use because it is usually a waste product of calving. A bovine placenta is very large and can support at least several full days of training work. The variety of vessel diameters allows various types of vascular training exercises. Unlike human placental vessels, bovine placental vessel walls have elastic fibers and are much thicker than both human placental and cerebral arteries. However, bovine placental vessels are not so markedly different from those in the human placenta and are useful. In fact, bovine placenta may provide a very excellent substrate for training exercises that simulate carotid and peripheral vascular arterial grafts.

If human placenta is not available, bovine placenta can easily be used for practice, and it is readily available in communities that contain dairy farms. There are at least 10 dairy farms within a 30-mile radius of Phoenix, Arizona, and it is likely that most neurosurgical training centers are in metropolitan areas that have similar, convenient, surrounding dairy distribution networks. In our experience, the dairy farms have been extremely cooperative, and the acquisition time (even with same-day arrangement in many instances), including driving to obtain placentas, is less than 1 hour. Procuring a human placenta depends on collaboration with the hospital's obstetrics department. Once communication is established and approved by the ethics committee, several human placentas per week are usually available, which is more than enough for practice. The total preparation time needed to wash and trim the placenta is about 15 minutes.

\section{Validation}

The number of studies on new simulation models is increasing, but most of the models have significant shortfalls in terms of methodology and design. ${ }^{18}$ Previous studies noted that for evidence-based medicine techniques, the face, content, and construct validities should be examined as the first step for evaluating the benefit of a surgical simulation model before integrating the model into a training curriculum. ${ }^{10}$

Validity measures reveal the instructive value of the simulation. Face validity relates to the realism of the simulator, and content validity is a judgment of the appropriateness of the simulator as a teaching modality. The values for face and content validity were high for this training model, as they were the upper grades for the surveys. Construct validity indicates whether the simulator is able to distinguish between experienced and inexperienced surgeons. ${ }^{21}$ In this study, quantitative anatomical and histological assessments and model validation were performed.

The results of the validity assessment confirmed that assessment of the training system by untrained participants could not be a reliable measure for assessing the face validity of the task, which is reasonable and serves more or less as a control measure. Because untrained participants are unfamiliar with the peculiarities of microvascular neurosurgical procedures, they could not reliably estimate the similarities or differences between the simulated and actual surgical tasks. Thus, to determine the face validity of the construct, we used answers only from the 17 trained participants. The absence of differences between the groups in the self-assessment of the performance only emphasizes this aspect, and supports the inevitable need for an objective performance measure, which was performed in our study using the NOMAT scale by a nonparticipant.

The NOMAT ${ }^{10}$ scores confirmed the training model as reliable, and the scale held validity to support the training model as beneficial as well as the assessment tool as being appropriate. We could distinguish easily between experienced and inexperienced performers on the model using this scale. Logistic regression analysis was used to assess a predictive statistical model, which is shown in Figure 14. By using the NOMAT score, this model predicted allocation to either the trained or untrained group. The transitional score in this model was found to be 50 points, meaning that those with a score of 50 have a $50 \%$ chance to be actually "trained" and a 50\% chance to be "untrained". Those who score $>50$ points have a greater chance to be actually trained and the opposite is true for a score $<50$ points. This relation is not linear, as shown in Figure 14. Concurrent validity demonstrates that the skills acquired during the training reflect performance in the operative room. We did not assess concurrent validity due to the inherent limitations of assessing unskilled or untrained personnel practicing such procedures in the operating room. However, we believe that our training model will enhance skills, and this enhancement should logically translate into increased confidence and the better performance of these surgical procedures in the operating room. ${ }^{6}$

\section{Limitations of the Placenta Microanastomosis Model}

Fresh human and bovine placentas can be used only for 1 to 2 weeks and are optimally used within the first 3 to 5 days. After this time, the vessels start to decay and the walls become weaker and more difficult to dissect and suture. The most important risk to the trainee regarding 
human placenta is infection. All biological tissues need to be screened for infectious diseases and used under the supervision of a research coordinator. The bypass simulation models presented herein only represent the vascular anastomosis simulation itself, without cadaveric training for neurosurgical techniques such as adjacent soft-tissue dissection or craniotomy. ${ }^{29}$ Another limitation of our model is the absence of natural brain pulsation; however, we believe that pressurized flow is sufficient for training because in most real-life scenarios vessel movements are restricted with microclips.

\section{Conclusions}

Microanastomosis simulation using the human placenta vascular anastomosis model has high face, content, and construct validities. A NOMAT score of more than 50 points indicated successful performance of the microanastomosis tasks. With some limitations, the human and bovine placenta model can conveniently provide useful and valid training for critical and sensitive microvascular techniques for the neurosurgeon in training.

\section{Acknowledgments}

We thank the staff of Neuroscience Publications at Barrow Neurological Institute for their valuable help in preparing and editing the paper. We are also thankful to the staff of the Neurosurgery Laboratory, Barrow Neurological Institute, for their help in organizing the bypass training courses and to William Bichard, Barrow Neurological Institute, for expert technical assistance. We are grateful to Ekaterina Antoshkina, MD, Chief of Pathology, and Alexander Novozhilov, $\mathrm{MD}, \mathrm{PhD}$, Director of the Irkutsk IvanoMatreninsky Childrens Hospital, Irkutsk, Russia, for providing human placentas. We also extend thanks to the Arizona Dairy Company, Mesa, Arizona, for providing bovine placentas.

\section{References}

1. Abla AA, Uschold T, Preul MC, Zabramski JM: Comparative use of turkey and chicken wing brachial artery models for microvascular anastomosis training. J Neurosurg 115:12311235,2011

2. Ayoubi S, Ward P, Naik S, Sankaran M: The use of placenta in a microvascular exercise. Neurosurgery 30:252-254, 1992

3. Banerjee AD, Thakur JD, Ezer H, Chittiboina P, Guthikonda B, Nanda A: Petrous carotid exposure with eustachian tube preservation: a morphometric elucidation. Skull Base 21:329-334, 2011

4. Bekov DB: [Individual anatomical variability of arteries of the fetal surface of human placenta.] Arkh Anat Gistol Embriol 98:32-43, 1990 (Russian)

5. Bekov DB: [Nomenclature of blood vessels of the chorion of mature human placenta.] Arkh Anat Gistol Embriol 100:96-102, 1991 (Russian)

6. Belykh E, Byvaltsev V: Off-the-job microsurgical training on dry models: Siberian experience. World Neurosurg 82:2024, 2014

7. Burke GM, Burke AM, Sherma AK, Hurley MC, Batjer HH, Bendok BR: Moyamoya disease: a summary. Neurosurg Focus 26(4):E11, 2009

8. Büyükmumcu M, Ustün ME, Seker M, Karabulut AK, Uysal YY: Maxillary-to-petrous internal carotid artery bypass: an anatomical feasibility study. Surg Radiol Anat 25:368-371, 2003

9. Chang SW, Abla AA, Kakarla UK, Sauvageau E, Dashti SR,
Nakaji P, et al: Treatment of distal posterior cerebral artery aneurysms: a critical appraisal of the occipital artery-to-posterior cerebral artery bypass. Neurosurgery 67:16-26, 2010

10. El Ahmadieh TY, Aoun SG, El Tecle NE, Nanney AD III, Daou MR, Harrop J, et al: A didactic and hands-on module enhances resident microsurgical knowledge and technical skill. Neurosurgery 73 (Suppl 1):51-56, 2013

11. Goldstein M: Use of fresh human placenta for microsurgical training. J Microsurg 1:70-71, 1979

12. Hino A: Training in microvascular surgery using a chicken wing artery. Neurosurgery 52:1495-1498, 2003

13. Kalani MY, Zabramski JM, Hu YC, Spetzler RF: Extracranial-intracranial bypass and vessel occlusion for the treatment of unclippable giant middle cerebral artery aneurysms. Neurosurgery 72:428-436, 2013

14. Kalani MY, Zabramski JM, Nakaji P, Spetzler RF: Bypass and flow reduction for complex basilar and vertebrobasilar junction aneurysms. Neurosurgery 72:763-776, 2013

15. Kanazawa R, Teramoto A: The realization of preferable operative working space through the microsurgical training with rats - the importance of the process. Surg Neurol 71:380-387, 2009

16. Kawashima M, Rhoton AL Jr, Tanriover N, Ulm AJ, Yasuda A, Fujii K: Microsurgical anatomy of cerebral revascularization. Part I: anterior circulation. J Neurosurg 102:116-131, 2005

17. Kim BJ, Kim ST, Jeong YG, Lee WH, Lee KS, Paeng SH: An efficient microvascular anastomosis training model based on chicken wings and simple instruments. J Cerebrovasc Endovasc Neurosurg 15:20-25, 2013

18. Kirkman MA, Ahmed M, Albert AF, Wilson MH, Nandi D, Sevdalis N: The use of simulation in neurosurgical education and training. A systematic review. J Neurosurg 121:228246, 2014

19. Kivipelto L, Niemelä M, Meling T, Lehecka M, Lehto H, Hernesniemi J: Bypass surgery for complex middle cerebral artery aneurysms: impact of the exact location in the MCA tree. J Neurosurg 120:398-408, 2014

20. Kwok JC, Huang W, Leung WC, Chan SK, Chan KY, Leung $\mathrm{KM}$, et al: Human placenta as an ex vivo vascular model for neurointerventional research. J Neurointerv Surg 6:394399, 2014

21. McDougall EM: Validation of surgical simulators. J Endourol 21:244-247, 2007

22. Mutoh T, Ishikawa T, Ono H, Yasui N: A new polyvinyl alcohol hydrogel vascular model (KEZLEX) for microvascular anastomosis training. Surg Neurol Int 1:74, 2010

23. Nakaji P: The necessity of technical excellence and safety in EC-IC bypass surgery. World Neurosurg 82:577-578, 2014

24. Olabe J, Olabe J, Sancho V: Human cadaver brain infusion model for neurosurgical training. Surg Neurol 72:700-702, 2009

25. Oliveira Magaldi M, Nicolato A, Godinho JV, Santos M, Prosdocimi A, Malheiros JA, et al: Human placenta aneurysm model for training neurosurgeons in vascular microsurgery. Neurosurgery 10 (Suppl 4):592-601, 2014

26. Parray T, Martin TW, Siddiqui S: Moyamoya disease: a review of the disease and anesthetic management. J Neurosurg Anesthesiol 23:100-109, 2011

27. Pinar YA, Govsa F: Anatomy of the superficial temporal artery and its branches: its importance for surgery. Surg Radiol Anat 28:248-253, 2006

28. Romero FR, Fernandes ST, Chaddad-Neto F, Ramos JG, Campos JM, Oliveira Ed: Microsurgical techniques using human placenta. Arq Neuropsiquiatr 66:876-878, 2008

29. Russin JJ, Mack WJ, Carey JN, Minneti M, Giannotta SL: Simulation of a high-flow extracranial-intracranial bypass using a radial artery graft in a novel fresh tissue model. Neurosurgery 71 (2 Suppl Operative):ons315-ons320, 2012 
30. Sekhar LN, Bucur SD, Bank WO, Wright DC: Venous and arterial bypass grafts for difficult tumors, aneurysms, and occlusive vascular lesions: evolution of surgical treatment and improved graft results. Neurosurgery 44:1207-1224, 1999

31. Sekhar LN, Natarajan SK, Ellenbogen RG, Ghodke B: Cerebral revascularization for ischemia, aneurysms, and cranial base tumors. Neurosurgery 62 (6 Suppl 3):1373-1410, 2008

32. Spetzler R, Chater N: Occipital artery-middle cerebral artery anastomosis for cerebral artery occlusive disease. Surg Neurol 2:235-238, 1974

33. Tanriover N, Kawashima M, Rhoton AL Jr, Ulm AJ, Mericle RA: Microsurgical anatomy of the early branches of the middle cerebral artery: morphometric analysis and classification with angiographic correlation. J Neurosurg 98:1277-1290, 2003

34. Yaşargil MG: Microneurosurgery. New York: Thieme Stratton, 1984

\section{Disclosures}

This research was supported with funds from the Barrow Neurological Foundation, the Women's Board of the Barrow Neurological Foundation, and in part by the Newsome Family
Endowment in Neurosurgery held by Dr. Preul. Dr. E. Belykh is supported by scholarship funds from the Council of the President of the Russian Federation for grants in support of young Russian scientists (SP-156.2013.4). Drs. E. Belykh and Lei are supported by funds from the Barrow Neurological Foundation. Dr. Hai Sun is supported by the Christopher Getch Fellowship awarded by the Congress of Neurological Surgeons.

\section{Author Contributions}

Conception and design: Preul, E Belykh. Acquisition of data: E Belykh, Lei, Safavi-Abbasi, Yagmurlu, R Almefty, Sun. Analysis and interpretation of data: E Belykh. Drafting the article: E Belykh, Lei. Critically revising the article: Preul, K Almefty, Spetzler, Nakaji. Reviewed submitted version of manuscript: Preul. Statistical analysis: E Belykh, Lei. Administrative/techni$\mathrm{cal} / \mathrm{material}$ support: Preul, O Belykh, Byvaltsev. Study supervision: Preul, Byvaltsev, Nakaji.

\section{Correspondence}

Mark C. Preul, c/o Neuroscience Publications, Barrow Neurological Institute, St. Joseph's Hospital and Medical Center, 350 W. Thomas Rd., Phoenix, AZ 85013. email: neuropub@dignity health.org. 